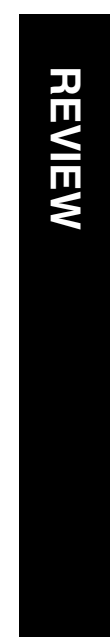

\section{Ketorolac therapy for the prevention of acute pseudophakic cystoid macular edema: a systematic review}

T Yilmaz', M Cordero-Coma² and MJ Gallagher ${ }^{3}$

Eye (2012) 26, 252-258; doi:10.1038/eye.2011.296; published online 18 November 2011

To assess the effectiveness of ketorolac $v$ s control for prevention of acute pseudophakic cystoid macular edema (CME). The following databases were searched: Medline (1950-June 11, 2011), The Cochrane Library (Issue 2, 2011), and the TRIP Database (up to 11 June 2011), using no language or other limits. Randomized controlled clinical trials (RCTs) were included that consisted of patients with acute pseudophakic cystoid macular edema, those comparing ketorolac with control, and those having at least a minimum follow-up of 28 days. In the four RCTs evaluating ketorolac vs control,

${ }^{1}$ Department of Ophthalmology, Stony Brook, NY, USA

2Department of Ophthalmology, Hospital de León, León, Spain

${ }^{3}$ The Hermitage Medical Clinic, Dublin, Ireland

Correspondence: T Yilmaz, Department of Ophthalmology, Stony Brook University, 33 Research Way, East Setauket, NY 11733, USA Tel: + 1631576 7858; Fax: + 1631444 4089; E-mail: taygan.yilmaz@ gmail.com

Received: 24 August 201 Accepted: 30 September 2011

Published online: 18 November 2011 treatment with ketorolac significantly reduced the risk of CME development at the end of treatment ( $\sim 4$ weeks) compared to control $(P=0.008 ; 95 \%$ confidence interval (0.03-0.58)). When analyzed individually, each individual study was statistically nonsignificant in its findings with the exception of one study. When the pooled relative risk was calculated, the large sample size of this systematic review led to overall statistical significance, which is attributable to the review's large sample size and not to the individual studies themselves. In this systematic review of four RCTs, two of which compared ketorolac with no treatment and two of which evaluated ketorolac $v s$ placebo drops, treatment with ketorolac significantly reduced the risk of developing CME at the end of $\sim 4$ weeks of treatment compared with controls. These results, however, should be interpreted with caution considering the paucity of large randomized clinical trials in the literature.
Keywords: pseudophakia; cystoid macular edema; ketorolac

\section{Introduction}

Despite advances in technique and surgical materials, cystoid macular edema (CME) is the most frequent cause of reduced vision following uneventful modern cataract surgery, with a seemingly rare incidence of $0.1-2.35 \% .{ }^{1,2}$

Although the main triggering factor is thought to be surgical trauma of intraocular tissues by inducing release of inflammatory mediators, other possible mechanisms such as photic retinopathy or vitreous traction have also been implicated. ${ }^{3}$ The rupture of the blood-aqueous barrier causes diffusion of prostaglandins and other inflammatory mediators into the vitreous cavity, which induces a cascade of inflammatory events with subsequent rupture of the blood-retinal barrier and CME generation in some patients. Several postoperative therapeutic regimens of topical antiinflammatory drugs, mainly including non-steroidal anti-inflammatory drugs (NSAIDs) and steroids, are aimed at reducing postoperative inflammatory events, including CME. ${ }^{4}$

The possibility, however, that there may be a synergistic effect makes it difficult to draw strong conclusions in relation to the efficacy of either of these groups of drugs alone in preventing CME. NSAIDs cause inhibition of prostaglandin synthesis and release by inhibiting the conversion of arachidonic acid to 
prostaglandin via the cyclooxygenase pathway. ${ }^{5}$ NSAIDs also suppress polymorphonuclear cell ability to move and chemotaxis in addition to decreasing expression of inflammatory cytokines and mast cell degranulation. ${ }^{6}$ Moreover, they also inhibit intraoperative miosis during cataract surgery, which decreases the risk of iris damage and intraoperative complications. ${ }^{7}$

Rossetti et $a l^{4}$ previously demonstrated the therapeutic benefit of NSAIDs and corticosteroids in both the prevention and treatment of CME by means of a meta-analysis. A Cochrane systematic review demonstrated that ketorolac was effective for chronic CME. ${ }^{8}$ More specifically, several randomized controlled clinical trials (RCTs) have revealed the potential benefit of one of these topical NSAIDs, ketorolac tromethamine (Acular LS, Allergan Inc., Irvine, CA, USA), in the management of acute pseudophakic CME. ${ }^{9-12}$ The purpose of this systematic review is to assess the effectiveness of ketorolac vs control in the treatment of acute pseudophakic CME (necessitating therapeutic intervention within 4 months of CME onset). ${ }^{13-15}$

\section{Materials and methods}

\section{Databases, search terms, limits, and special strategies}

Medline was searched via OVID (1950-June Week 2, 2011) using a Cochrane highly sensitive search (phases one and two) with an acute pseudophakic cystoid macular edemaassociated term along with ketorolac. Additional literature searches using the terms postoperative cystoid macular edema and ketorolac were conducted also using the following databases: The Cochrane Library (Issue 2, 2011; searched up to June 2011) in addition to LILACS, and the TRIP Database (up to 11 June 2011). No limits were used in these searches.

\section{Additional search methods}

The ClinicalTrials.gov. registry, Google Scholar, and EMBASE (all up to 11 June 2011) were searched using the terms pseudophakic cystoid macular edema and ketorolac. The references of germane articles and the abstracts of meetings of the Association for Research in Vision and Ophthalmology (1975-present) were reviewed manually. Experts and key authors were identified and contacted to seek information regarding ongoing trials and additional studies relevant to our review.

\section{Study selection}

All authors independently identified potentially relevant studies and evaluated each trial according to predetermined eligibility criteria. Studies were considered for inclusion if they were RCTs comparing the intervention of ketorolac with control for prevention of acute pseudophakic CME. Studies were excluded if they analyzed ketorolac in a chronic CME setting. The minimum follow-up time required for inclusion was at least 4 weeks. Studies were not limited based on language, country of origin, or status of publication. Discrepancies were resolved by mutual review and consensus.

\section{Data abstraction}

All authors used a standardized abstraction form to abstract data independently. Pertinent data included study population characteristics (age, gender, number of patients and eyes in study, and location), intervention groups, comparison groups, outcome variables, and duration and completeness of follow-up. ${ }^{16}$ Discrepancies were resolved through extensive discussion to reach a conclusion.

\section{Quality assessment}

A Jadad quality assessment was conducted for included trials by assessing the methodological quality of RCTs. ${ }^{17}$ In this assessment, quality was based on seven questions, with a score range of $0-5$, with higher scores indicating higher study quality. These questions examined the appropriateness of three main study characteristics: randomization, blinding, and participant withdrawals / dropouts. Three reviewers independently assessed the four included studies based on the questions, and discrepancies were resolved in discussion to ultimately reach a consensus. A study was deemed to be of high quality if it had a Jadad score of $\geq 3$ points.

\section{Assessment of risk of bias}

All authors assessed various potential sources of systematic bias by constructing a risk of bias summary (Figure 2). ${ }^{18}$ The following biases were considered: differences in how the comparison groups were assembled (selection bias), how care was provided in the comparison groups versus care in the groups receiving the intervention (performance bias), how outcomes were assessed between the comparison groups (detection bias), how comparison groups differed in terms of the loss of participants from the study (attrition bias), and how investigators reported their data (reporting bias).

\section{Data synthesis}

Pooled relative risk

Considering that a dichotomous outcome variable was analyzed, a fixed-effects model using the Mantel-Haenszel method was employed and a pooled 
relative risk was calculated, with a $P$-value $<0.05$ being considered significant (The Review Manager (RevMan Computer Program) version 5.0 for Mac. The Nordic Cochrane Centre, The Cochrane Collaboration, Copenhagen, Denmark, 2008).

\section{Publication bias}

Publication bias was assessed through visual inspection of a funnel plot, which graphed the effect size for the outcome of CME incidence, looking for asymmetry that would suggest a paucity of small studies with modest effect sizes (RevMan software version 5.1.2).

\section{Results}

\section{Results of search}

Figure 1 is a flow diagram of all studies that were considered to be a part of the review. An extensive literature search yielded 37 studies, and 23 of these studies were excluded based on abstract review. Fourteen studies were retrieved for more detailed review, of which 10 were excluded based on a comprehensive full-text review. As the flow diagram indicates, four studies met all of the inclusion criteria and were included in the review.

\section{Characteristics of included studies}

The characteristics of the four included studies are outlined in Table 1. Study sizes ranged from 100 to 546 patients. Patient characteristics were similar across all trials, with mean ages ranging from 64 to 74 and gender being fairly equally represented. All studies used ketorolac as the intervention. In the comparison group, a control was used in all four studies. One study used three disparate dosing regimens of ketorolac. ${ }^{10}$ Two of the four studies were double-blinded. Duration of follow-up ranged from 4 to 13 weeks. Additionally, all of the studies had attrition rates ranging from 0 to $20 \%$.

\section{Methodological quality of included studies}

All four studies included in the review were assessed for methodological quality based on the Jadad score. There was a fair degree of variability in study quality: two studies had a Jadad score of 3, one study had a Jadad score of 2, yet one study was given a Jadad score of 4 (Table 1). Three out of the four studies were deemed to have high quality, with a Jadad score of at least three. Studies with diminished Jadad quality scores were not double-blinded, did not use appropriate randomization techniques, or both.

\section{CME incidence}

In the Almeida et $a l^{12}$ study, the primary end point was the difference in total macular volume as determined by optical coherence tomography (OCT) between baseline and one month in the ketorolac and control (only steroid and antibiotic) groups. Ketorolac $0.5 \%$ was used on a three times daily dosing regimen 28 days postoperatively. No preoperative ketorolac was administered in either group. When used in this prophylactic manner, the investigators determined that ketorolac $0.5 \%$ was more beneficial than control in

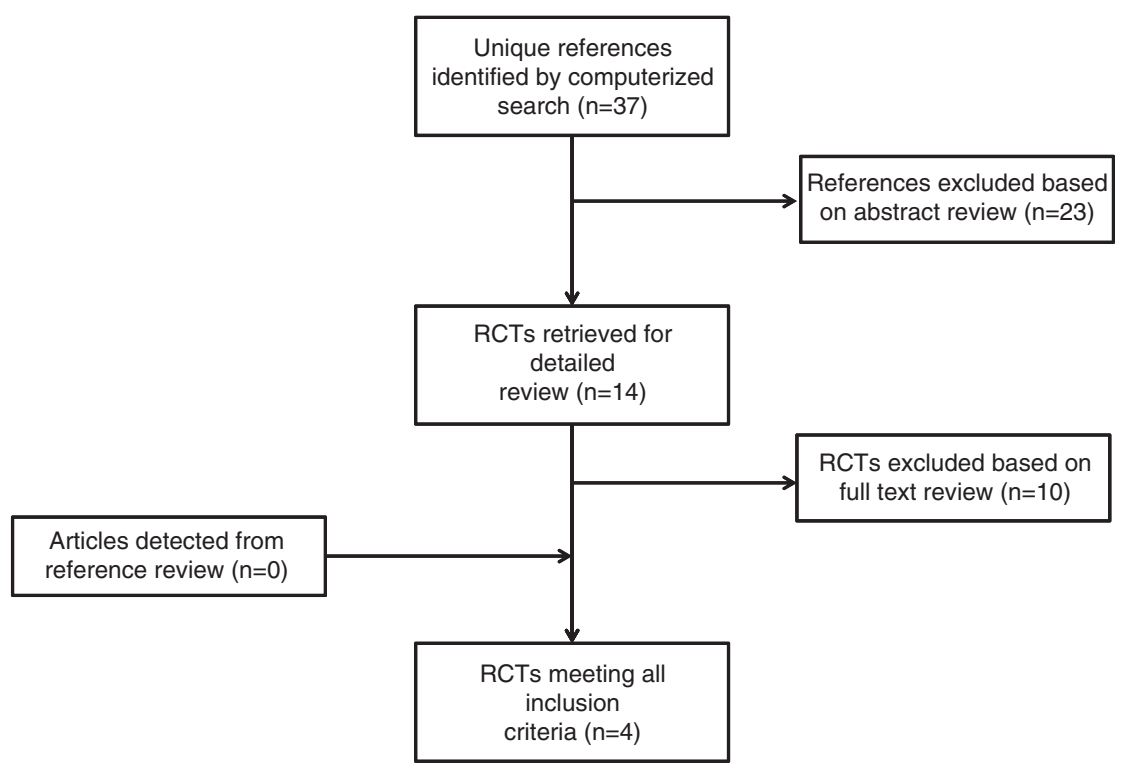

Figure 1 Flow diagram showing the progression of the study. 
Table 1 Characteristics of RCTs evaluating ketorolac for acute pseudophakic cystoid macular edema

\begin{tabular}{|c|c|c|c|c|c|c|c|c|c|c|c|c|}
\hline $\begin{array}{l}\text { Author } \\
\text { (location) }\end{array}$ & Year & Exposure & $\begin{array}{l}\text { Dose } \\
(\%)\end{array}$ & $\begin{array}{c}N \\
\text { (patients/ } \\
\text { eyes) }\end{array}$ & $\begin{array}{c}N \\
\text { (eyes) }\end{array}$ & $\begin{array}{l}\text { Mean age } \\
\text { (years) }\end{array}$ & $\begin{array}{l}\text { Sex } \\
(\% M)\end{array}$ & $\begin{array}{c}\text { Blinding } \\
\text { of } \\
\text { intervention }\end{array}$ & $\begin{array}{l}\text { Blinding of } \\
\text { outcome } \\
\text { assessment }\end{array}$ & $\begin{array}{l}\text { Duration } \\
\text { of follow-up } \\
\text { (weeks) }\end{array}$ & $\begin{array}{c}\text { Completeness } \\
\text { of follow-up } \\
(\%)\end{array}$ & $\begin{array}{c}\text { Quality } \\
\text { assessment } \\
\text { (Jadad score) }\end{array}$ \\
\hline $\begin{array}{l}\text { Chatziralli et al } \\
\text { (Greece) }^{11}\end{array}$ & 2011 & $\begin{array}{l}\text { Ketorolac } \\
\text { Control }^{\mathrm{a}}\end{array}$ & $\begin{array}{c}0.5 \text { (TID) } \\
\text { N/A }\end{array}$ & 138 & $\begin{array}{l}70 \\
68\end{array}$ & $\begin{array}{l}74.3 \\
74.0\end{array}$ & $\begin{array}{l}61.4 \\
58.9\end{array}$ & $\mathrm{~N}$ & $\mathrm{~N}$ & 4 & 100 & 2 \\
\hline $\begin{array}{l}\text { Donnenfeld et al } \\
(\mathrm{USA})^{10}\end{array}$ & 2006 & $\begin{array}{l}\text { Ketorolac (1) } \\
\text { Ketorolac (2) } \\
\text { Ketorolac (3) }_{\text {Control }^{\mathrm{c}}}\end{array}$ & $\begin{array}{c}0.4(\mathrm{QID}) \\
0.4(\mathrm{QID}) \\
0.4(\mathrm{QID}) \\
\mathrm{N} / \mathrm{A}\end{array}$ & 100 & $\begin{array}{l}25 \\
25 \\
25 \\
25\end{array}$ & 64.2 & 45.0 & Y & Y & 13 & $\mathrm{~N} / \mathrm{A}$ & 4 \\
\hline $\begin{array}{l}\text { Wittpenn et al } \\
(\text { USA })^{9}\end{array}$ & 2008 & $\begin{array}{l}\text { Ketorolac } \\
\text { Control }^{c}\end{array}$ & $\begin{array}{c}0.4 \text { (QID) } \\
\text { N/A }\end{array}$ & 546 & $\begin{array}{l}268 \\
278\end{array}$ & 70.0 & 46.70 & Y & Y & 4 & 98 & 3 \\
\hline
\end{tabular}

Abbreviations: QID, four times daily; TID, three times daily; M, male; N, number; N/A, not applicable; N, no; Y, yes.

${ }^{\text {a}}$ Represents no treatment beyond steroid and antibiotic.

${ }^{b}$ The Donnenfeld study separated the ketorolac treatment group into three sections. Please refer to the Results section for further details.

'Represents placebo drops.

decreasing macular swelling as measured by OCT and, as such, the ketorolac group had a lower incidence of patients with acute pseudophakic CME.

The aim of the study designed by Chatziralli et $a l^{11}$ was to evaluate the benefit of adding a ketorolac $0.5 \%$ to an antibiotic/steroid combination after uneventful phacoemulsification, adopting a weekly follow-up, to gain insight into the optimal duration of postoperative treatment and to examine whether risk factors for inflammation exist. The ketorolac was administered TID for 3 days preoperatively and for 28 days postoperatively. The control group received tobramycin $0.3 \%$-dexamethasone $0.1 \%$, one drop QID alone. The study demonstrated that the frequency of inflammationrelated signs did not differ between the two groups at any time point. There was no evidence of clinically significant CME in either group. The study concluded that the addition of ketorolac did not seem to offer any additional benefit and that 4 weeks appeared as an adequate treatment interval.

Donnenfeld et $a l^{10}$ assessed the clinical benefit, relative efficacy, and pharmacokinetic-response curve of preoperative and postoperative ketorolac tromethamine $0.4 \%$ to improve outcomes during and after the cataract surgery. In all, 100 patients were randomized in a double-masked fashion to four groups of 25 patients as follows:

(a) Ketorolac $0.4 \%$ (QID) for 3 days preoperatively and three times every $15 \mathrm{~min}$ in the hour before surgery

(b) Ketorolac $0.4 \%$ (QID) for 1 day preoperatively and every $15 \mathrm{~min}$ in the hour before surgery

(c) Ketorolac $0.4 \%$ every $15 \mathrm{~min}$ in the hour before surgery

(d) Placebo every $15 \mathrm{~min}$ in the hour before surgery.
No patient receiving ketorolac $0.4 \%$ for 1 or 3 days developed CME compared with $12 \%$ of patients in the control group and $4 \%$ in the 1-h group. The study concluded that the preoperative use of ketorolac $0.4 \%$ for 3 days followed by 1 day of predosing provided optimum efficacy and superior outcomes relative to $1-\mathrm{h}$ pretreatment and a control.

Wittpenn et $a l^{9}$ designed a prospective, randomized, investigator-masked, and multicenter trial to evaluate whether adding perioperative topical ketorolac tromethamine $0.4 \%$ improves the cataract surgery outcomes relative to topical steroids alone in patients without known risk factors for CME. The patients were randomized to receive either prednisolone acetate $1 \%$ four times daily alone $(n=278)$, or combined with ketorolac $0.4 \%(n=268)$. The ketorolac $0.4 \%$ was administered for 3 days preoperatively and four doses every $15 \mathrm{~min}$ in the hour before surgery, and postoperatively for 4 or 6 weeks. The study demonstrated that no patients in the ketorolac/steroid group and five patients in the placebo drop/steroid group had clinically apparent CME. Based on OCT measurements, six patients in the placebo drop/steroid group had evidence of CME compared with the other group who had none. The authors concluded that adding perioperative ketorolac to postoperative prednisolone significantly reduces the incidence of CME in cataract surgery patients already at low risk for the condition.

\section{Adverse events}

Relatively minor adverse events that were reported included pain, burning, tearing, stinging, and intraocular pressure elevation, none of which reached statistical significance. Wittpenn et al. ${ }^{9}$ reported two serious 
adverse events: a case of endophthalmitis and the death of a study participant (unrelated to the study medication).

\section{Discussion}

Based on our extensive literature review, this is the first documented systematic review of RCTs specifically evaluating ketorolac for prevention of acute pseudophakic CME. The current medical literature suggests that a consensus has not been reached regarding the appropriate methods in preventing acute pseudophakic CME. There are still opposing views regarding whether patients should be treated prophylactically with an NSAID or not given any medication.

After pooling the results, it was found that treatment with ketorolac significantly reduced the risk of CME development compared with control, two of which compared ketorolac with no treatment and two of which evaluated ketorolac $v$ s placebo, at the end of treatment (typically at 4 weeks $)(P=0.008 ; 95 \%$ confidence interval (CI), 0.03-0.58) (Figure 2). Three of four trials were estimable, though nonstatistical inclusion of the Chatziralli study ${ }^{11}$ made no difference to the overall results when re-analyzed in a subgroup analysis.

However, the authors stress caution with the interpretation of these results. When analyzed individually, each individual study was statistically nonsignificant in its findings, with the exception of the Wittpenn study. ${ }^{9}$ When the pooled relative risk was calculated, the large sample size of this systematic review led to overall statistical significance. The authors attribute this to the review's large sample size and not to the individual studies themselves. Furthermore, the included studies were all determined to be significantly underpowered based on a power of $80 \%$ and an $\alpha$ significance of 0.05. The Almeida, Donnenfeld, and Wittpenn studies were determined to have a statistical power of $2.5 \%, 45.1 \%$, and $53.1 \%$, respectively. $9,10,12$
The power of the Chatiziralli study ${ }^{11}$ was inestimable because of the fact that there were no incidents of CME in either group.

In the risk of bias summary, most of the trials were considered essentially devoid of any major biases related to the study execution (Figure 3). Publication bias was adjudged to be fairly nonexistent according to visual inspection of a funnel plot. However, this conclusion should be taken with caution given the number of included studies.

Nevertheless, there is a questionable risk of additional biases in the Donnenfeld and Wittpenn studies because of their paid consultancies for Allergan, Inc., at the time of their study investigations. ${ }^{9,10}$ This compromise of

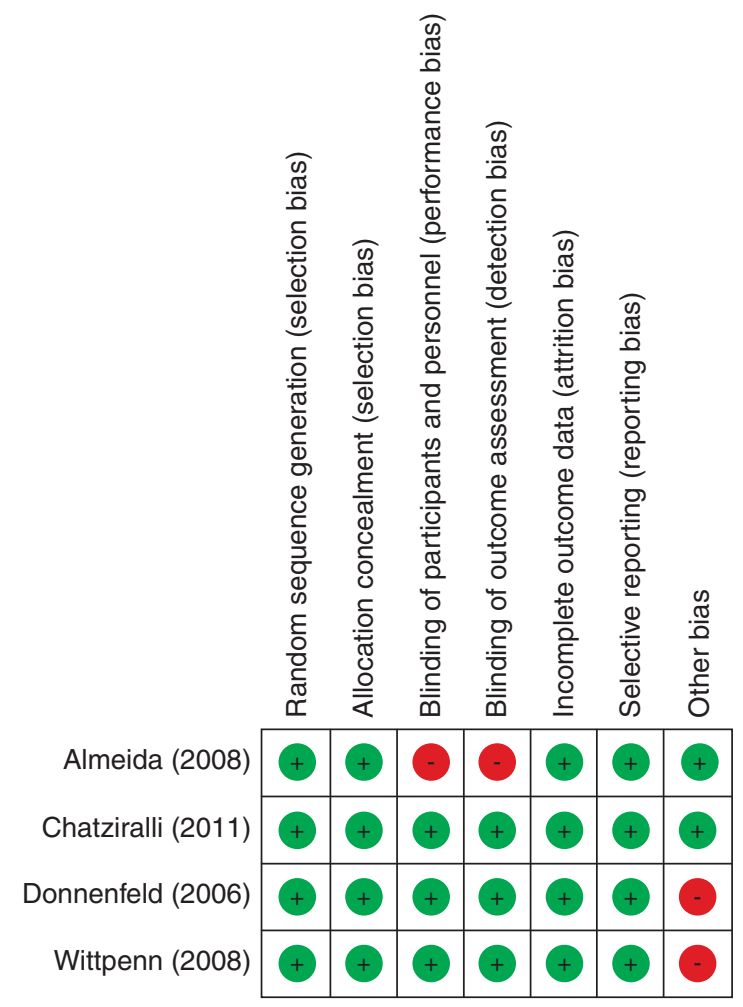

Figure 3 Risk of bias summary across all studies. (' + ': low risk of bias, '-': high risk of bias).

\begin{tabular}{|c|c|c|c|c|c|c|c|c|c|c|}
\hline \multirow{3}{*}{$\begin{array}{l}\text { Study or Subgroup } \\
\text { Almeida (2008) }\end{array}$} & \multicolumn{2}{|c|}{ Ketorolac } & \multicolumn{2}{|c|}{ Control } & \multirow{3}{*}{$\begin{array}{l}\text { Weight } \\
12.1 \%\end{array}$} & \multirow{3}{*}{$\begin{array}{c}\begin{array}{c}\text { Risk Ratio } \\
\text { M-H, Fixed, 95\% Cl }\end{array} \\
0.33[0.01,8.00]\end{array}$} & \multirow{2}{*}{\multicolumn{4}{|c|}{$\begin{array}{c}\text { Risk Ratio } \\
\text { M-H, Fixed, } 95 \% \text { Cl }\end{array}$}} \\
\hline & \multirow{2}{*}{$\begin{array}{c}\text { Events } \\
0\end{array}$} & \multirow{2}{*}{$\begin{array}{c}\text { Total } \\
53\end{array}$} & \multirow{2}{*}{$\frac{\text { Events }}{1}$} & \multirow{2}{*}{$\begin{array}{c}\text { Total } \\
53\end{array}$} & & & & & & \\
\hline & & & & & & & & $\longrightarrow$ & & \\
\hline Chatziralli (2011) & 0 & 70 & 0 & 68 & & Not estimable & & & & \\
\hline Donnenfeld (2006) & 1 & 75 & 3 & 25 & $36.3 \%$ & $0.11[0.01,1.02]$ & & & & \\
\hline Wittpenn (2008) & 0 & 268 & 6 & 278 & $51.5 \%$ & $0.08[0.00,1.41]$ & 4 & & - & \\
\hline Total $(95 \% \mathrm{Cl})$ & & 466 & & 424 & $100.0 \%$ & $0.12[0.03,0.58]$ & & & & \\
\hline Total events & 1 & & 10 & & & & & & & \\
\hline Heterogeneity: Chi $^{2}=$ & $=2(P=0$ & $9) ; 1^{2}=$ & & & & & $\vdash$ & & & \\
\hline Test for overall effect & $(P=0.00$ & & & & & & 0.01 & 0.1 & 10 & 100 \\
\hline
\end{tabular}

Figure 2 Forest plot displaying pooled summary estimates of CME development in patients treated with ketorolac compared with control at the end of the treatment period. 
objectivity raises concerns when interpreting these trials. As shown in a review of 370 RCTs, studies funded by for-profit organizations were 5.3 times more likely (95\% CI, 2.0-14.4) than non-profit organizations to recommend the experimental drug as the treatment of choice. ${ }^{19,20}$

The authors decided not to conduct a meta-analysis in the four included trials owing to their substantial heterogeneity:

- Two RCTs used ketorolac tromethamine $0.4 \%$ whereas the other two employed ketorolac tromethamine $0.5 \%$

- Two RCTs utilized placebo drops as their control group compared with the other two RCTs using only a steroid and antibiotic

- Variation in sample size

- Differences in time when ketorolac was administered (pre-, peri-, and/or postoperatively)

- Only one RCT analyzed contrast sensitivity ${ }^{9}$

- Two RCTs assessed CME via OCT ${ }^{9,12}$

- All but Almeida et al ${ }^{12}$ evaluated best-corrected visual acuity.

There is a need for more long-term trials evaluating ketorolac in large groups in order to strengthen the evidence in favor of ketorolac to prevent acute pseudophakic CME development. Moreover, ketorolac should be compared head-to-head with other NSAIDs if the ophthalmologic community deems NSAIDs as an integral component of surgical cataract care. Given the large number of cataract procedures performed annually (1.8 million were performed on Medicare beneficiaries alone in 2004), the use of any NSAID in this setting without legitimate justification would result in significant costs to Medicare and insurance plans, as well as to uninsured patients. ${ }^{21}$

Ideally, future trials should compare ketorolac with both placebo drops and with no treatment within the same trial. These trials should be sufficiently large and with longer follow-up periods in order to achieve the power necessary to illustrate any potential difference in outcome among these preventive strategies for acute pseudophakic CME. If future studies support Flach's ${ }^{22}$ findings that outcomes at 7 years suggest that the natural history of CME is spontaneous resolution, the question of whether or not ketorolac should be used for acute pseudophakic CME would be rendered moot.

\section{Conclusion}

In this systematic review of four RCTs, treatment with ketorolac significantly reduced the risk of developing $\mathrm{CME}$ at the end of $\sim 4$ weeks of treatment compared with controls. These results, however, should be taken with caution considering the paucity of large randomized clinical trials in the literature.

\section{Conflict of interest}

The authors declare no conflict of interest.

\section{Acknowledgements}

We would like to express our deepest gratitude to Robert A Honkanen, MD for his clinical insight in the preparation of this manuscript.

\section{References}

1 Loewenstein A, Zur D. Postsurgical cystoid macular edema. Dev Ophthalmol 2010; 47: 148-159.

2 Nishino M, Eguchi H, Iwata A, Shiota H, Tanaka M, Tanaka T. Are topical steroids essential after an uneventful cataract surgery? J Med Invest 2009; 56(1-2): 11-15.

3 Guex-Crosier Y. The pathogenesis and clinical presentation of macular edema in inflammatory diseases. Doc Ophthalmol 1999; 97(3-4): 297-309.

4 Rossetti L, Chaudhuri J, Dickersin K. Medical prophylaxis and treatment of cystoid macular edema after cataract surgery. The results of a meta-analysis. Ophthalmology 1998; 105(3): 397-405.

5 Gaynes BI, Fiscella R. Topical nonsteroidal anti-inflammatory drugs for ophthalmic use: a safety review. Drug Saf 2002; 25(4): 233-250.

6 Perianin A, Roch-Arveiller M, Giroud JP, Hakim J. In vivo effects of indomethacin and flurbiprofen on the locomotion of neutrophils elicited by immune and non-immune inflammation in the rat. Eur J Pharmacol 1984; 106(2): 327-333.

7 Guzek JP, Holm M, Cotter JB, Cameron JA, Rademaker WJ, Wissinger $\mathrm{DH}$ et al. Risk factors for intraoperative complications in 1000 extracapsular cataract cases. Ophthalmology 1987; 94(5): 461-466.

8 Sivaprasad S, Bunce C, Wormald R. Non-steroidal antiinflammatory agents for cystoid macular oedema following cataract surgery: a systematic review. Br J Ophthalmol 2005; 89(11): 1420-1422.

9 Wittpenn JR, Silverstein S, Heier J, Kenyon KR, Hunkeler JD, Earl M. A randomized, masked comparison of topical ketorolac $0.4 \%$ plus steroid vs steroid alone in low-risk cataract surgery patients. Am J Ophthalmol 2008; 146(4): 554-560.

10 Donnenfeld ED, Perry HD, Wittpenn JR, Solomon R, Nattis A, Chou T. Preoperative ketorolac tromethamine $0.4 \%$ in phacoemulsification outcomes: pharmacokinetic-response curve. J Cataract Refract Surg 2006; 32(9): 1474-1482.

11 Chatziralli IP, Papazisis L, Sergentanis TN. Ketorolac plus tobramycin/dexamethasone versus tobramycin/ dexamethasone after uneventful phacoemulsification surgery: a randomized controlled trial. Ophthalmologica 2011; 225(2): 89-94.

12 Almeida DR, Johnson D, Hollands H, Smallman D, Baxter S, Eng KT et al. Effect of prophylactic nonsteroidal antiinflammatory drugs on cystoid macular edema assessed using optical coherence tomography quantification of total macular volume after cataract surgery. J Cataract Refract Surg 2008; 34(1): 64-69.

13 Flach AJ, Dolan BJ, Irvine AR. Effectiveness of ketorolac tromethamine $0.5 \%$ ophthalmic solution for chronic aphakic 
and pseudophakic cystoid macular edema. Am J Ophthalmol 1987; 103(4): 479-486.

14 Flach AJ, Stegman RC, Graham J, Kruger LP. Prophylaxis of aphakic cystoid macular edema without corticosteroids. A paired-comparison, placebo-controlled double-masked study. Ophthalmology 1990; 97(10): 1253-1258.

15 Rho DS. Treatment of acute pseudophakic cystoid macular edema: diclofenac versus ketorolac. J Cataract Refract Surg 2003; 29(12): 2378-2384.

16 Dickersin K, Scherer R, Lefebvre C. Identifying relevant studies for systematic reviews. BMJ 1994; 309(6964): 1286-1291.

17 Jadad AR, Moore RA, Carroll D, Jenkinson C, Reynolds DJ, Gavaghan DJ et al. Assessing the quality of reports of randomized clinical trials: is blinding necessary? Control Clin Trials 1996; 17(1): 1-12.
18 Higgins J, Green S. Cochrane Handbook for Systematic Reviews of Interventions 4.2.6. Section 6. The Cochrane Library, Issue 42006.

19 Als-Nielsen B, Chen W, Gluud C, Kjaergard LL. Association of funding and conclusions in randomized drug trials: a reflection of treatment effect or adverse events? JAMA 2003; 290(7): 921-928.

20 Kaufman SR. Bias and sponsored research. Ophthalmology 2008; 115(2): 412-413; author reply 413.

21 AAO. American Academy of Ophthalmology. Cataract in the Adult Eye, Preferred Practice Pattern. 2006. http://www.aao.org/ppp.

22 Flach AJ. The incidence, pathogenesis and treatment of cystoid macular edema following cataract surgery. Trans Am Ophthalmol Soc 1998; 96: 557-634. 